\title{
Clinical Profile of Patients Undergoing Mass Closure and Layered Closure Techniques in Laparotomies
}

\author{
Ganesh S Bhavikatti', Raghavendra Gupta GHV \\ ${ }^{1}$ Assistant Professor, Department of Surgery, GIMS, Gadag, Karnataka, ${ }^{2}$ Senior Resident, Department of Surgery, JJMMC, Davangere, Karnataka.
}

\section{Abstract}

Background: Linen and Cotton were already in use. Silk was the next suture of choice in non-absorbable suture range. It became very popular because of its excellent handling properties. It was extensively used in all surgical procedures including Cardiovascular Surgery. Halstead was its main proponent. Thorough clinical examination of the patients was made and recorded. Particular attention was given to note the anaemia, nutritional status, jaundice, respiratory tract infections. Apart from the examination of the system involved, routine examination of CVS, RS \& CNS were carried out. Subjects and Methods: History taking was followed as a routine in all cases admitted to the wards.Plain X-ray abdomen, Contrast X-rays like barium meal, Upper GI endoscopy and Abdominal ultrasound and CT scan were done in necessary cases.However in emergency cases, only the investigations necessary for supporting the diagnosis were employed. Results: In this study mid line incision was done in 39 patients, $65 \%$ of patients, Right Para Median incision in 18 patients $30 \%$, left Para median in 3 patients, $5 \%$. In this study in mass closure group a mean time taken $(\mathrm{min}) 15.73$ was required for the closure of the incision with standard deviation of 1.82 .In the layered closure group mean time taken $(\mathrm{min})$ was 25.03 with a standard deviation of 1.83 . Conclusion: The age of the patients ranged from 15-65 years. Out of 60 patients 16 were in the age group of <30 years, 13 were 30-39 years, 11 were $40-49$ years and 20 were $>50$ years.

Keywords: Clinical Profile, Mass Closure and Layered Closure Techniques, Laparotomies.

Corresponding Author: Dr. Raghavendra Gupta GHV, Senior Resident, Department of Surgery, JJMMC, Davangere, Karnataka.

Received: July 2019

Accepted: July 2019

\section{Introduction}

In surgery, the choice of suture materials has been largely empirical. One learns and craft of surgery from one's chief and the tendency is to use the suture materials used by him. Thus the use of suture material has not always been scientific.

One of the earliest Indian Surgical texts written by Susruta described in detail round bodied, curved and straight needles. Sutures were made from flax, hemp, bark fibre or hair.

Egyptian Literature of about 1600 B.C. mentions the use of linen strips coated with an adhesive mixture of honey and flour thereby creating the original skin closure strips.

Aurelius Cornelius Celsus, a Roman and a Medical Journalist wrote a monumental book in medicine about A. D. 30 and it is known as De Re Medicina. Celsus mentions that sutures were of ancient origin and should be soft and not over twisted, so that they may be more easy on the part. Whether he was referring to linen or wool is uncertain. He also described small metal clips similar to Michel Clips of today. ${ }^{[1]}$

Galen of Pergamon, A.D. 150, in his work, De Methodo Medendi, comments for the first time on the use of catgut but makes it plain that it was known to the ancients. Catgut made from the twisted intestines of herbivorous animals is still used today and indeed, accounts for nearly half the usage of all sutures and ligatures. Although its most important characteristic is that it is absorbed and digested by body enzymes this fact was not discovered until the eighteenth century. The ancients used it because it was strong and easily available from any musician. The origin of the word 'catgut' is obscure and all we can say definitely is that it never had anything to do with cats! One suggestion is that it is a corruption Of "Kitgut" the kit being an early form of musical instrument similar to violin.

The first great Arabian, Rhazes started his life as a minstrel and a storyteller. Later on in life he turned to medicine. He used catgut for suturing the abdomen; natural material for a lute player to choose. ${ }^{[2]}$

Avicenna, known as the Prince of Physicians, contributed to suture development by his realization that traditional materials like linen and thread, when used in presence of gross infection, tended to break down rapidly. In search of more suitable materials, he turned to pig's bristles and so invented the first monofilament suture.

The Prince of Surgeons was undoubtedly Albucasis, born in A.D. 936. He used sutures and was the first to describe a double suture, a technique still used today.

Ambrose Pare described a method of dry suturing for wounds of the face. This consisted of sticking strips of plaster down each side of the wound and then sewing the strips together. The object of this indirect stitch was obviously cosmetic. ${ }^{[3]}$ 
John Hunter (1728-93) was of the opinion that sutures were basically undesirable but if needed they should be interrupted sutures. He preferred where possible to bandage or use sticking plaster across the wound.

Following Hunter's preference for adhesive strips to close or assist in the closing of a wound, Physick experimented with adhesive strips made of leather. He noticed that these strips were dissolved after contact with fluids discharged from the wounds and it occurred to him that ligatures which would eventually dissolve in the body would be of considerable benefit. $^{[4]}$

He then experimented on a horse with a ligature of back skin, which proved successful. He followed this by trying kid parchment, vanished leather, tendon and but found that catgut did not dissolve easily enough. His experiments were historic, for no one had previously considered the possibility of an absorbable suture, which would perform its function and then disappear. As mentioned earlier, catgut had been used previously because it was strong and readily available, although Galen came near the truth when he advocated its use as a material, which caused less pus than many others.

By 1867, Lister had formulated and published his answer and now the long 'Carbolic Crusade' began. But Lister's scientific acumen was not limited to antisepsis. Two years later he published an article, 'Observations of Ligature of Arteries on the Antiseptic System'. He was aware of Physick's work and had himself noticed that fragments of glass or needles inadvertently left in a wound did not give rise to suppuration. He conceived that harmful bacteria must lie within the interstices of the silk and if they could be killed a ligature could be left in the body. Up to that time the ends of a ligature were left long, protruding out of the wound. After a while the tightly tied end of the artery or vein necrosed and sloughed off from the healthy tissue to be withdrawn with the ligature when it was pulled out of the wound. With such a system the chances of the dreaded secondary haemorrhage were, of course, high. With his new antiseptic ligature Lister hoped that he could cut the end of the ligature short and leave it Implanted, either to be absorbed like dead tissue or encapsulated like the lead from fowling piece. ${ }^{[5]}$

Lister had one further contribution to make to the manufacture of surgical catgut. In an attempt to delay the absorption of catgut so that wound and blood vessels would have longer to heal in safety, Lister turned to the leather trade and found they used chromic acid to tan leather. This he incorporated into his formulation.

By 1900 the catgut industry was firmly established in Germany due to the use of sheep intestine in their sausage industry.

Of the many technical advances in the suture manufacture little more need be said other than the introduction of sterilization by irradiation in 1960 using Cobalt 60 isotope. This allowed sutures to be sealed in their final package and then sterilized, thereby eliminating the dangers and difficulties of aseptic transfers.

Linen and Cotton were already in use. Silk was the next suture of choice in non-absorbable suture range. It became very popular because of its excellent handling properties. It was extensively used in all surgical procedures including Cardiovascular Surgery. Halstead was its main proponent.

These natural non-absorbable sutures had certain disadvantages and with the technological advancements, Polyester and Polyamide were introduced and replaced previous non-absorbable sutures in many surgical procedures. Polyester was made available as braided, coated and non-coated. Recently, polyester is also available as Monofilament in fine sizes. Later on Monofilament Polypropylene was made available after extensive research. It is a very strong material fulfilling many characteristics of an ideal suture material. It is very extensively used today along with Polyester and Polyamide almost replacing the use of Silk, Cotton and Linen.

Then came the era of Synthetic absorbable sutures. In 1970 and 1971, the first suture material from Polyglycolic acid was introduced into clinical practice. 6

Subsequently, Glycolide and Lactide were combined in suitable proportions to develop a suture known as Polyglactin 910. Later on, this was coated to make it smooth. Further research resulted in development of PDS (Polydioxanone), VICRYL Rapide (Polyglactin 910) and MONOCRYL (Polyglecaprone 25). PDS was further modified and improved to PDS Il.

\section{Subjects and Methods}

\section{History}

History taking was followed as a routine in all cases admitted to the wards. History was taken regarding diseases like diabetes mellitus, hypertension, jaundice, tuberculosis and other chest infections and also the time of onset of the disease. History of smoking, prolonged use of steroids was also taken into account.

\section{Clinical Examination}

Thorough clinical examination of the patients was made and recorded. Particular attention was given to note the anaemia, nutritional status, jaundice, respiratory tract infections. Apart from the examination of the system involved, routine examination of CVS, RS \& CNS were carried out.

\section{Investigations}

As a routine the following investigations were done for all cases

- Blood: Hb\%, TC, DC, ESR, BT, Clotting Time, Blood grouping and Rh typing.

- FBS, PPBS (for diabetics)

- LFT for protein values and level of bilirubin.

- Blood urea, serum creatinine

- Urine : for albumin, sugar, microscopy

- ECG and chest X-ray PA view

\section{Special Investigations}

- Plain X-ray abdomen in erect posture was used in acute abdominal cases suspected of hollow viscus perforation or intestinal obstruction.

- Contrast X-rays like barium meal were used whenever necessary.

- Upper GI endoscopy was used in suitable cases for diagnosis.

- Abdominal ultrasound and CT scan were done in necessary cases.

However in emergency cases, only the investigations necessary for supporting the diagnosis were employed. 


\section{Results}

The age of the patients ranged from 15-65 years. Out of 60 patients 16 were in the age group of <30 years, 13 were 30 39 years , 11 were $40-49$ years and 20 were $>50$ years. Mean age in group-1 - 39.6 years and in group-2 - 42.96 years.

\begin{tabular}{|c|c|c|c|}
\hline \multicolumn{2}{|c|}{ Socio-demographic variables } & $\begin{array}{l}\text { Group-1 } \\
\text { Mass Closure } \\
\text { Technique } \\
\text { N=30 }\end{array}$ & $\begin{array}{l}\text { Group-2 } \\
\text { Layered Closure } \\
\text { Technique } \\
\mathbf{N}=30\end{array}$ \\
\hline \multicolumn{2}{|c|}{ Age (Mean \&Sd) } & $39.6 \pm 14.7$ & $42.96 \pm 15.02$ \\
\hline \multirow{4}{*}{$\begin{array}{l}\text { Age } \\
\text { Categories }\end{array}$} & $<30 \mathrm{yrs}$ & 10 & 6 \\
\hline & $30-39$ & 4 & 9 \\
\hline & $40-49$ & 7 & 4 \\
\hline & $50 \&$ Above & 9 & 11 \\
\hline
\end{tabular}

In this series of 60 patients 42 were male and 18 were female. i.e $.70 \%$ of the study group comprised of male patients.

\section{Table 2: Sex Distribution}

\begin{tabular}{|l|l|l|l|}
\hline Sex & $\begin{array}{l}\text { Group-1 } \\
\text { Mass Closure } \\
\text { Technique N=30 }\end{array}$ & $\begin{array}{l}\text { Group-2 } \\
\text { Layered Closure } \\
\text { Technique N=30 }\end{array}$ & Percentage \\
\hline Male & 17 & 25 & $70 \%$ \\
\hline Female & 13 & 5 & $30 \%$ \\
\hline
\end{tabular}

In the group-1, 20 patients underwent emergency surgery, while 10 underwent elective surgery.

In the group-2, 21 patients underwent emergency surgery while 9 underwent elective surgery.

Overall $68.33 \%$ underwent emergency surgery and $31.66 \%$ underwent elective surgery.

Table 3: Distribution of cases according to the nature of operation and closure technique

\begin{tabular}{|l|l|l|l|l|}
\hline & $\begin{array}{l}\text { Group-1 } \\
\text { Mass } \\
\text { Closure } \\
\text { Technique } \\
\text { N=30 }\end{array}$ & $\begin{array}{l}\text { Group-2 } \\
\text { Layered } \\
\text { Closure } \\
\text { Technique } \\
\mathbf{N = 3 0}\end{array}$ & $\begin{array}{l}\text { Percentage } \\
\text { For 60 } \\
\text { cases }\end{array}$ & $\begin{array}{l}\text { Statistical } \\
\text { Analysis }\end{array}$ \\
& 20 & 21 & $68.33 \%$ & \\
\hline Emergency & 20 & 9 & $31.66 \%$ & NS \\
\hline Elective & 10 & 9.07, \\
\hline
\end{tabular}

In this study mid line incision was done in 39 patients, $65 \%$ of patients, Right para Median incision in 18 patients $30 \%$, left para median in 3 patients, $5 \%$.

\begin{tabular}{|c|c|c|c|c|}
\hline Type of incision & $\begin{array}{l}\begin{array}{l}\text { Group-1 } \\
\text { mass } \\
\text { closure } \\
\text { techniqu }\end{array} \\
\mathrm{e} \\
\mathrm{N}=30\end{array}$ & $\begin{array}{l}\begin{array}{l}\text { Group-2 } \\
\text { layered } \\
\text { closure } \\
\text { techniqu }\end{array} \\
\mathrm{e} \\
\mathrm{N}=\mathbf{3 0}\end{array}$ & $\begin{array}{l}\text { Percentag } \\
\text { e }\end{array}$ & $\begin{array}{l}\text { Statistica } \\
\text { I analysis }\end{array}$ \\
\hline Mid Line & 20 & 19 & $65 \%$ & \multirow{3}{*}{$\begin{array}{l}\chi^{2}=0.58 \\
\text { NS }\end{array}$} \\
\hline $\begin{array}{l}\text { Right Para } \\
\text { Median }\end{array}$ & 8 & 10 & $30 \%$ & \\
\hline Left Para median & 2 & 1 & $5 \%$ & \\
\hline
\end{tabular}

In this study in mass closure group an mean time taken ( $\min ) 15.73$ was required for the closure of the incision with standard deviation of 1.82 .
In the layered closure group mean time taken (min) was 25.03 with a standard deviation of 1.83 .

The $\mathrm{p}$ value is $<0.000$, which is stastically significant.

Table 5: Time taken for closure in mass and layered closure techniques

\begin{tabular}{|l|l|l|l|}
\hline Time Taken in Min & $\begin{array}{l}\text { Group-1 } \\
\text { Mass Closure } \\
\text { Technique } \\
\mathbf{N}=\mathbf{3 0}\end{array}$ & $\begin{array}{l}\text { Group-2 } \\
\text { Layered } \\
\text { Closure } \\
\text { Technique } \\
\mathbf{N}=30\end{array}$ & $\begin{array}{l}\text { Statistical } \\
\text { Analysis }\end{array}$ \\
\cline { 1 - 3 } Mean & 15.73 & 25.03 & $\mathrm{t}=19.75$, \\
\hline Std Deviation & 1.82 & 1.83 & $\mathrm{P}<0.000$ \\
\hline
\end{tabular}

\section{Discussion}

A rich literature upon the subject of the placing, making and closing of the abdominal incision attests to the many methods which surgeons have employed. The existing variations in technique are evidence that no one method is so pre-eminently superior that it's advantages will force every surgeon to adopt it at the expense of abandoning a more familiar method. End results must be very similar or less effective techniques would have been abandoned years ago. ${ }^{[7]}$

In all cases of mass closure technique, the suture material used Proline No. 1 on round body needle. Suturing was started at the upper end of the incision downwards with continuous sutures. All layers of the abdominal wall except skin and subcutaneous tissue were included in single layer. Large bites were taken about $1 \mathrm{~cm}$ from the wound edge with a distance of $1 \mathrm{~cm}$ between the sutures.

In all cases of layered closure technique, in midline incisions layer by layer closure of abdominal wall with an anatomical approximation from deep to superficial layers was done. Peritoneum was closed with No. 2-0 Vicryl, continuous sutures. Linea Alba was closed separately with No. 1 Proline with continuous sutures. In paramedian incisions the peritoneum and posterior layer of rectus sheath was closed with Vicryl No.2.0 by continuous locking sutures. The anterior layer of rectus sheath was closed with No.1 Prolene by continuous locking sutures.

End points were wound infection, burst abdomen (wound dehiscence) in the two groups and also the time taken for closure.

The age of the patients ranged from 15-65 years. Out of 60 patients 16 were in the age group of $<30$ years, 13 were 3039 years, 11 were $40-49$ years and 20 were $>50$ years. Mean age in group-1 - 39.6 years and in group- $2-42.96$ years. 42 were male and 18 were female. i.e $.70 \%$ of the study group comprised of male patients. In the group-1, 20 patients underwent emergency surgery, while 10 underwent elective surgery. In the group-2,21 patients underwent emergency surgery while 9 underwent elective surgery. Overall $68.33 \%$ underwent emergency surgery and $31.66 \%$ underwent elective surgery.

Smead performed in 1900 what is believed to be the first for - near closure of the abdomen, a technique often referred to in the united states as Smead jones method. ${ }^{[8]}$

Dambrin reported the decreased incidence of wound evisceration with a mass layered technique in 1937. ${ }^{[9]}$

In 1941, Jones and associates reported only 1 burst abdomen 
in 81 operation after steel wire closure with interrupted mass 'far and near' sutures incorporating all layers of abdominal wall apart from the skin.

A study carried out at Cleveland clinic by Hoerr et al identified in 1951 that there was little to choose between the abdominal incision closed with mass closure technique and that closed in layers so far as the immediate post operative complications and the post operative pain where concerned through mass closures were simpler to execute and required only $3 / 4$ th as much time as a layered closure. ${ }^{[10]}$

A single layer wire closure of abdominal incisions was used by Spencer and Sharp in a group of 293 patients. The authors concluded (in 1963) that single layer closure was a reliable and effective method for incisions in which deficient wound healing was expected.

Experimental studies by Higgins et al (1969) showed that abdominal incisions closed by mass suture technique had greater strength than those closed with conventional layer method. ${ }^{[11]}$

In an experimental analysis by Dudley in 1970, it was concluded that mass closure was more resistant to disruption in the early period and did not seem to be a disadvantage when healing was nearly complete. ${ }^{[12]}$

Kirk, in 1972, presented a comparative study of vertical laparotomy wound closure, using chromic catgut by conventional layer technique in 540 cases (method 1) and closure in single layer with monofilament nylon (method 2) in 327 cases. The difference in the rate of burst abdomen observed in his series after method 1 (3.88\%) and method 2 (.31\%) was highly significant as it was more than three times the standard error of the difference between the two rates (1: 10). ${ }^{[13]}$

Goligher et al in 1975 conducted a controlled clinical trial of three methods of closing laparotomy wounds and concluded that "mass suture with wire was probably the most secure method of abdominal wound closure."[14]

Nayman, in 1976, conducted a prospective study consisting of 616 cases to evaluate the technique of mass single layer closure of abdominal wounds. Complete wound breakdown occurred in two patients $(.3 \%)$ and partial wound breakdown occurred in two patients $(.3 \%)$, a total incidence of $(.6 \%) .{ }^{[15]}$ Irvin et al conducted a prospective clinical study on abdominal wound healing involving 200 patients. The patients were randomly allocated to a layered closure or mass closure. They concluded in 1977 that the incidence of incisional hernia and wound dehiscence were similar after the two methods of abdominal wound closure. ${ }^{[16]}$

Pollock et al conducted a prospective randomized trial involving 305 patients and Concluded in 1979 that laparotomy closure by a single continuous layer of sutures was satisfactory. ${ }^{[17]}$

Wallace et al in 1980 concluded that mass closure of midline abdominal wounds using Snead Jones technique was superior to layered closure in prevention of wound disruption. ${ }^{[18]}$

Narsimharao et al in 1983 recommended single layer abdominal wound closure technique as a routine, particularly in poor risk patients and contaminated wounds. ${ }^{[19]}$

Shepherd JH et al after a prospective study involving 200 patients concluded in 1983 that continuous 1-Iayer abdominal closure method was simple, time saving, and successful and that it carried a low complication rate for patients at high risk for postoperative evisceration. ${ }^{[20]}$

A randomized controlled clinical trial conducted by Ausobsky et al in 1985 concluded that layered closure of a paramedian incision resulted in a lower incidence of incisional hernia than mass closure of a midline incision. ${ }^{[21]}$

S.B. Sharma et al conducted a comparative study of two different techniques of abdominal wound closure. One was single layer closure and the other was the conventional layered closure technique. They concluded in 1986 that single layer closure technique was superior because it was easy, saved time and was associated with lesser postoperative complications as compared to conventional layered closure technique. ${ }^{[22]}$

Taube $\mathrm{M}$ et al after a prospective study, concluded in 1987 that the rate of wound in jaundiced patients could be reduced much using the mass closure technique. ${ }^{[23]}$

Nasher studied 112 patients and reported in 1988 that single layer closure of laparotomy wounds was more effective than classical layered closure. ${ }^{[24]}$

\section{Conclusion}

The age of the patients ranged from 15-65 years. Out of 60 patients 16 were in the age group of $<30$ years, 13 were 30 39 years, 11 were $40-49$ years and 20 were $>50$ years. Mean age in group-1 - 39.6 years and in group- $2-42.96$ years. 42 were male and 18 were female. i.e $.70 \%$ of the study group comprised of male patients. In the group-1, 20 patients underwent emergency surgery, while 10 underwent elective surgery.

\section{References}

1. "A comparative study of single layer closure and conventional layered closure of laparotomy wounds". Journal of Evolution of Medical and Dental Sciences 2013; Vol. 2, Issue 40, October 07; Page: 7695- 7709.

2. Ellis $\mathrm{H}$, Heddle R. Does the peritoneum need to be closed at laparotomy? Br J Surg 1977; 64(10):733-6.

3. Jenkins TP. The burst abdominal wound $-\mathrm{A}$ mechanical approach. $\mathrm{Br} \mathrm{J}$ Surg 1976; 63(11):873-6.

4. Zinner M.J and Moseley. Maingot's Abdominal Operations 10thEdt. Vol 1. Chapter 11. Pg 395-424.

5. Gilbert JM, Ellis H, Foweraker S. Peritoneal closure after lateral paramedian incision. Br J Surg 1987; 74(2):113-5.

6. Michael J Zinner, Stanley W. Ashley Maingot's Abdominal Operations. 11th edition. 2007 by McGraw-Hill Education.

7. Gray's anatomy the anatomical basis of clinical practice 14th Edt. pg 1055.

8. Robbins and Cortan "Pathalogical Basis Of Disease Edt. 7th Chapter 3 ,pg 110-114.

9. Dambrin C., "Sutures des paroidabdominales a L'aide de fils de ferperdus", Mem ,Acad ,Chir 1937;63:1269.

10. Hoerr S.O., Allen R., and Allen K. "The closure of the abdominal incision: A comparison with wire and layer closure with silk, Surgery, 1951;30: 166-173.

11. Higgins G.A., Antkowaik J.G., and Esterkyn S.H. "A Clinical and laboratory study of abdominal wound closure and dehiscence, Arch.Surg., 1969; 98:421-427.

12. Dudley H.A.F. "Layered and Mass Closure of the abdominal wall: A theoretical and Experimental analysis".Br. J. Surg .,1970;57(9):664-667.

13. Krik R.M. "Effect of method of opening and closing the abdomen on incidence of wound bursting. Lancet, 1972;2: 352-353.

14. Goligher J.C., Irvin T.T., Johnston D., de Dombal F.T., Hill G.L., Horrocks J.C "A Controlled clinical trial of three methods of closure of laparotomy wounds.Br J Surg $1975 ; 62: 823-829$.

15. Nayman J. "Mass Single Layer Closure of Abdominal Wounds". Med J. Aust., 1976; 1: 183-186. 
16. Irvin T,T. Stoddard C.J., Greaney M.G., Duthie H.L. "Abdominal wound healing: a prospective clinical study". Br. Med. J. 1977; 2: 351352.

17. Pollock A.V., Greenall M.J., Mary Evans. "Single-layer mass closure of major laparotomies by continuous suturing". J.R. Soc Med 1979; 72: 889-893.

18. Wallace D., Hernandez W., Schlaerth J.B., Nalick R.N., Morrow C. Paul. "Prevention of Abdominal Wound Disruption utilizing the Smead-Jones Closure Technique". ObstetGynecol 1980; 56 (2): 226230.

19. Narasimharao K.L., Chatterjee H. and Satya Prakash. "Single layer abdominal wound closure in children". Aust. N.Z. J. surg. 1983; 53:577579.
20. Shepherd J.H., Cavanagh D., Riggs D., Praphat H. and Wisniewski B.J. "Abdominal wound closure using a non absorbable single-layer technique". Obstet Gynecol. 1983; 61(2): 284-252.

21. Ausobsky J.R., Evans M., Pollock A.V. "Does mass closure of midline laparotomies stand the test of time ? A random control clinical trial". Ann R Coll Surg Engl 1985; 67: 159-161.

22. Sharma S.B., Singh N., Usman M., Sogani K.C. "Single-layer abdominal wound closure". Indian Journal Surgery 48 (4): 149 — 151

23. Taube M., Ellis H. "Mass closure of abdominal wounds following major laparotomy in jaundiced patients". Ann R CollSurg Engl. 1987; 69(6):276-279.

24. Nasher A.A.W. "Single layer closure of abdominal laparotomy wounds" Tropical Doctor 1988; 18: 109-110.

Copyright: (C) the author(s), 2019. It is an open-access article distributed under the terms of the Creative Commons Attribution License (CC BY 4.0), which permits authors to retain ownership of the copyright for their content, and allow anyone to download, reuse, reprint, modify, distribute and/or copy the content as long as the original authors and source are cited.

How to cite this article: Bhavikatti GS, Gupta GHVR. Clinical Profile of Patients Undergoing Mass Closure and Layered Closure Techniques in Laparotomies. Acad. J Surg. 2019;2(1):37-41.

DOI: dx.doi.org/10.21276/ajs.2019.2.1.11 